\title{
Meconium Is a Source of Pro-Inflammatory Substances and Can Induce Cytokine Production in Cultured A549 Epithelial Cells
}

\author{
ARNOUT JAN de BEAUFORT, ASTRID C. BAKKER, MAARTEN J.D. van TOL, \\ BEN J. POORTHUIS, ALEXANDRA J. SCHRAMA, AND HOWARD M. BERGER \\ Neonatal Unit, Department of Pediatrics, Juliana Children's Hospital and Leiden University Medical \\ Center, 2506 LP The Hague, the Netherlands [A.J.d.B., A.C.B., A.J.S., H.M.B.], and Laboratories of \\ Immunology and Biochemistry, Department of Pediatrics, Leiden University Medical Center, 2300 RC \\ Leiden, the Netherlands [M.J.D.v.T., B.J.P.]
} \begin{abstract}
ABS
Inflammation plays an important role in the pathogenesis of
meconium aspiration syndrome, and pneumonitis is one of the major characteristics. We have previously shown that meconium has chemotactic properties because of the presence of IL-8. We hypothesize that IL-8 and other proinflammatory substances in meconium may amplify inflammation in meconium aspiration syndrome, inducing endogenous cytokine production by lung epithelial cells. We measured proinflammatory substances in first-pass meconium from healthy newborns and evaluated the effect of sterile meconium on cytokine production in cultured A549 alveolar epithelial cells in vitro. IL-1 $\beta$, IL-6, IL-8, and tumor necrosis factor- $\alpha$ were measured by ELISA, and heme was measured spectrophotometrically. After incubation of meconium samples with A549 cells, cytokine concentrations in the supernatant were measured. Meconium samples contained variable amounts of IL- $1 \beta$, IL- 6 , IL- 8 , tumor necrosis factor- $\alpha$, and heme. On stimulation of A549 cells with meconium, the IL-8 concentration in the culture supernatant significantly increased above baseline measurements, whereas tumor necrosis factor- $\alpha$ showed
\end{abstract}

a variable pattern and IL- $1 \beta$ or IL- 6 remained unchanged. There was no quantitative relationship between the concentration of the measured cytokines and heme in meconium and cytokine release by the A549 cells after meconium exposure. Meconium contains proinflammatory substances. All samples induced IL-8 release and some induced tumor necrosis factor- $\alpha$ release in cultured A549 epithelial cells. We speculate that proinflammatory substances in meconium can induce lung inflammation in meconium aspiration syndrome in two ways: directly via cytokines and heme present in meconium and indirectly by inducing cytokine release by the epithelial lung cells. (Pediatr Res 54: 491-495, 2003)
Abbreviations
MAS, meconium aspiration syndrome
MSAF, meconium-stained amniotic fluid
TNF- $\alpha$, tumor necrosis factor- $\alpha$
TMB, 3,5,3',5'-tetramethyl benzidine

One in every 10 full-term pregnancies ends with MSAF, and approximately $5 \%$ of neonates born with MSAF will develop MAS at birth or in the hours after delivery. MAS, a disease with high neonatal morbidity and mortality, is characterized by respiratory distress as a result of airway obstruction, pneumonitis, and (often) persistent pulmonary hypertension (1).

Inflammation plays an important role in the pathogenesis of MAS $(2,3)$, but the mechanism responsible for the inflammatory response is not fully understood. We have previously reported that IL-8 in meconium is responsible for in vitro

Received August 7, 2002; accepted March 7, 2003.

Correspondence: A.J. de Beaufort, M.D., Neonatal Unit, Department of Pediatrics, Juliana Children's Hospital and Leiden University Medical Center, PO Box 60605, 2506 LP The Hague, The Netherlands; e-mail: a.debeaufort@jkz-rkz.nl

Funded in part by a grant from "Gisela Thier Fonds."

DOI: 10.1203/01.PDR.0000082017.97479.39 chemotactic properties of meconium (4). Others have shown chemotactic activity of MSAF containing high levels of IL-8, TNF- $\alpha$, and IL- $1 \beta$ (5). Meconium is likely to contain other factors capable of inducing inflammation. One candidate could be the $\mathrm{Hb}$ breakdown product heme, which is a potent trigger of inflammation in mice (6). In addition, meconium may also contribute to the inflammatory process by inducing the production of inflammatory substances in the lungs. In a newborn rabbit model meconium has been shown to induce production of inflammatory cytokines and this might play a role in epithelial cell damage (7). Therefore, we hypothesize that meconium contains proinflammatory substances that can induce cytokine production in lung epithelial cells and trigger a cycle of inflammation in MAS.

The aim of this study was to measure proinflammatory substances in meconium from newborn infants and to evaluate 
the effect of meconium on in vitro cytokine production by cultured A549 alveolar epithelial cells.

\section{METHODS}

The study was approved by the scientific committee of the Department of Pediatrics of the Leiden University Medical Center.

Meconium. The first meconium passed from 23 unrelated healthy neonates (gestational age, 34-40 postmenstrual weeks) was collected after an uneventful delivery. The meconium was collected from the diaper into a sterile container within 30 min of passage. All samples were suspended in PBS at a concentration of $100 \mathrm{~g} / \mathrm{L}$. After sonication on ice and centrifugation $(3 \mathrm{~min}, 750 \times \mathrm{g}$ ), the sonicates were filtered $(8$ $\mu \mathrm{m}$; Millipore Products, Bedford, MA, U.S.A.) and stored at $-80^{\circ} \mathrm{C}$ until use.

Cytokine and heme assay. MAbs against IL-1 $\beta$, IL-6, IL-8, and TNF- $\alpha$ were purchased from the Central Laboratory of the Dutch Blood Transfusion Service (CLB), Amsterdam, the Netherlands. Other chemicals were obtained from Sigma Chemical Co. (St. Louis, MO, U.S.A.) and were of the highest purity available.

In separate ELISA plates (Titertek, Merlin Diagnostic Systems BV, Breda, the Netherlands), microwells were coated with MAbs against IL- $1 \beta$, IL-6, IL-8, and TNF- $\alpha$ (1:100) in $0.1 \mathrm{M}$ carbonate buffer, $\mathrm{pH} 9.6$, and incubated overnight at $4^{\circ} \mathrm{C}$. After extensive washing with PBS- $0.05 \%$ Tween-20, the wells were incubated with skimmed milk solution $(1 \% \mathrm{vol} / \mathrm{vol})$ for $2 \mathrm{~h}$ at room temperature. Every subsequent incubation, with samples diluted in PBS- $0.05 \%$ Tween- 20 with $5 \%$ casein (Sigma Chemical Co.), was performed at room temperature and followed by extensive washing of the wells with PBS$0.05 \%$ Tween-20 (three times). Next, the wells were incubated $(1 \mathrm{~h})$ with control samples of IL-6, IL-8, IL-1 $\beta$, and TNF- $\alpha$, dilutions of the meconium samples, or PBS. Then biotinlabeled rabbit IgG antibody to human IL-1 $\beta$, IL-6, IL-8, and TNF- $\alpha$ was incubated for $1 \mathrm{~h}$. After washing, horseradish peroxidase-conjugated streptavidin (streptavidin poly-HRP; CLB) was added (30 min). TMB $(100 \mu \mathrm{g} / \mathrm{mL}$, in $0.11 \mathrm{M}$ acetate buffer; Sigma Chemical Co.) was used as a substrate for horseradish peroxidase. The reaction was stopped by adding $0.8 \mathrm{M} \mathrm{H}_{2} \mathrm{SO}_{4}$. Optical densities were read at $450 \mathrm{~nm}$. Measurements were performed in triplicate. Data from at least three experiments are shown.

Heme assay. Samples were incubated with TMB in acetic acid $(10 \mathrm{~g} / \mathrm{L})$ and $\mathrm{H}_{2} \mathrm{O}_{2}(1 \% \mathrm{vol} / \mathrm{vol})$ for $20 \mathrm{~min}$. After dilution and incubation in acetic acid $(10 \% \mathrm{vol} / \mathrm{vol})$ for $10 \mathrm{~min}$, oxidized TMB was measured spectrophotometrically at $600 \mathrm{~nm}$.

Cell culture. A549 cells (human carcinoma cell line with features of alveolar epithelium, purchased from the American Type Culture Collection (ATCC, Rockville, MD, U.S.A.) were kindly provided by P.S. Hiemstra, Ph.D. (Department of Pulmonology, Leiden University Medical Center) and grown in monolayers in tissue culture flasks (Costar, Cambridge, MA, U.S.A.) at $37^{\circ} \mathrm{C}$ in a $5 \% \mathrm{CO}_{2}$ humidified atmosphere. $\mathrm{A} 549$ cells were maintained in RPMI 1640 (GIBCO, Invitrogen, Breda, the Netherlands) supplemented with L-glutamine (2
$\mathrm{mM})$, penicillin $\left(5 \times 10^{6} \mathrm{U} / \mathrm{L}\right)$, and streptomycin $(5 \mathrm{mg} / \mathrm{L}$; from Bio-Whittaker, Wakersville, MD, U.S.A.) and $10 \%$ heatinactivated FCS (GIBCO). The cells were passaged weekly after exposure to $0.25 \%(\mathrm{wt} / \mathrm{vol})$ trypsin, $0.1 \%$ (wt/vol) EDTA, and $40 \mu \mathrm{g} / \mathrm{L}$ versene.

Stimulation experiments. A549 cells were plated in 24-well tissue culture plates (Greiner, Frickenhausen, Germany) at a concentration of $0.8 \times 10^{5}$ cells/well $(1 \mathrm{~mL} /$ well $)$. At confluency, cells were rinsed with PBS and cultured overnight with serum-free RPMI medium. In a separate series of experiments, cytokine release in the supernatant by A549 cells was measured. Cells were incubated overnight with $5 \times$ diluted $(20 \mathrm{~g} / \mathrm{L})$ sterile meconium samples, IL-8 (20 ng/L), TNF- $\alpha$ ( $20 \mathrm{ng} / \mathrm{L})$, or heme $(5 \mu \mathrm{M})$ in RPMI (final concentrations). To evaluate the effect of incubation time, cells were cultured in the presence of three randomly selected sterile meconium samples, TNF- $\alpha$, or PBS for 1, 2, 6, and $24 \mathrm{~h}$.

In all experiments cell-free supernatants were collected and assayed by ELISA. Cell viability was assayed by counting cells in the presence of trypan blue.

Data analysis. Data are expressed as mean \pm SD. Sample groups are given as range (median). Statistical significance among sample groups was defined by Mann-Whitney test. A $p$ value less than 0.05 was considered significant.

\section{RESULTS}

Cytokines and heme. Twenty-three meconium samples were evaluated. Nine samples remained sterile in bacterial culture, and 14 showed bacterial contamination (no microbiologic identification was performed).

Levels of IL- $1 \beta$, IL-6, IL-8, and TNF- $\alpha$ in the meconium samples are shown in Figure 1. The cytokine concentrations varied markedly among samples. No significant differences in concentration were found between sterile and contaminated samples. Overall cytokine concentrations were as follows (range [median] in ng/L): IL-1 $\beta, 0.2-37$ (1.4); IL-6, 0-2 (0.6); IL-8, 1-380 (13); and TNF- $\alpha$, 1-300 (25). For sterile samples the values were IL- $1 \beta, 0.2-7$ (1.4); IL-6, 0-2 (1.4); IL-8, 5-380 (18); and TNF- $\alpha, 1-140$ (25). Heme was present in all samples $(0.2-40 \mu \mathrm{M}[1.0])$ with no significant differences between the sterile and contaminated samples (Fig. 1). No correlation between birth weight, gestational age, or sex and cytokine or heme concentrations was found.

Stimulation experiments. The effect of meconium on cytokine production by A549 cells in time was studied with three sterile meconium samples, containing, respectively, IL-8, 122, 5 , and $6 \mathrm{ng} / \mathrm{L}$; and TNF- $\alpha, 50,1$, and $6 \mathrm{ng} / \mathrm{L}$. At 6 and $24 \mathrm{~h}$ of incubation with 5-fold diluted meconium samples $(20 \mathrm{~g} / \mathrm{L})$, IL-8 levels in culture supernatants were higher in comparison with IL-8 levels present in the 5-fold diluted meconium samples $(p<0.01$; Fig. 2). This rise in concentration should be attributed to the release of IL- 8 by the A549 cells. After 6-24 $\mathrm{h}$ of incubation, TNF- $\alpha$ levels were not measurable in one supernatant, and less than $10 \mathrm{ng} / \mathrm{L}$ in the two others (data not shown). IL- $1 \beta$ and IL-6 were below the limit of detection $(<0.1 \mathrm{ng} / \mathrm{L})$ at any time (data not shown). Because a plateau was reached for the release of IL- 8 between 6 and $24 \mathrm{~h}$ of 


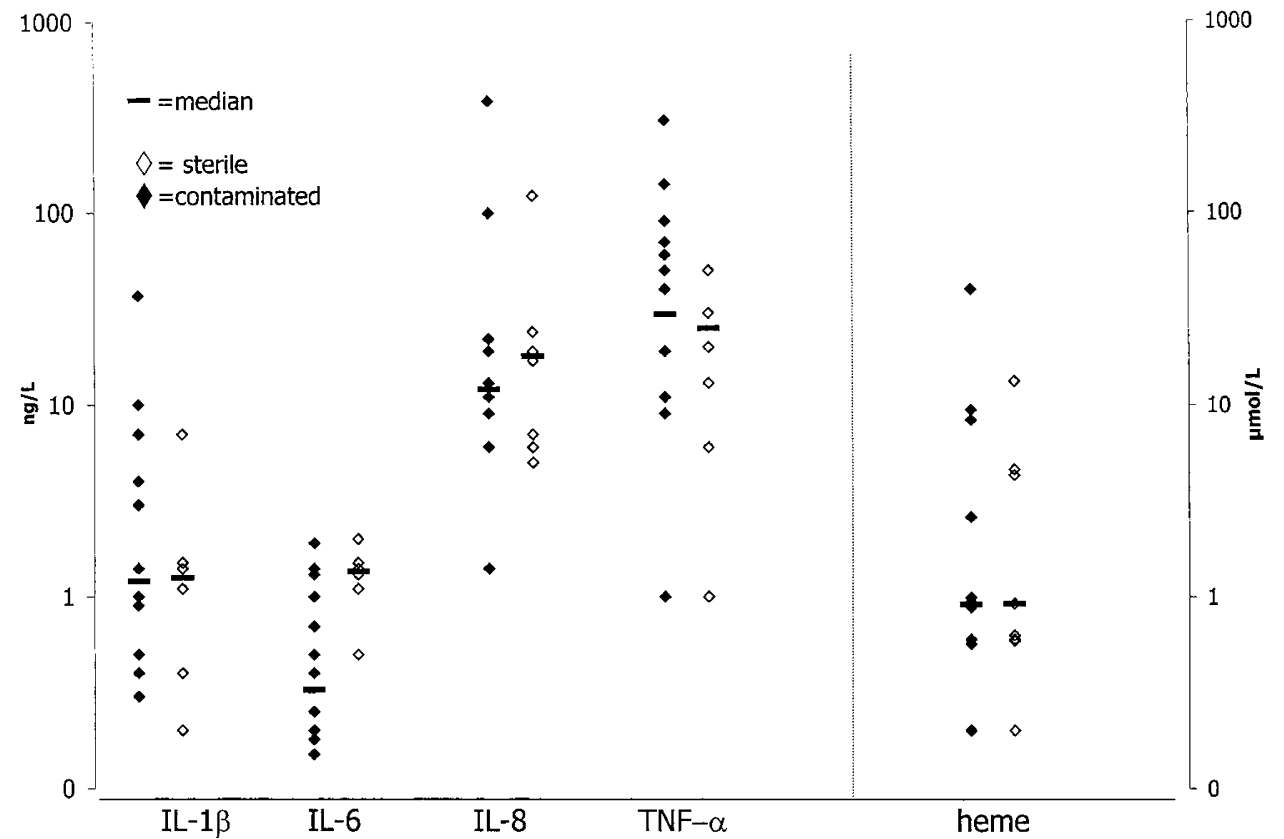

Figure 1. Cytokine (ng/L; left $y$ axis) and heme ( $\mu$ mol/L, right $y$ axis) levels in 23 meconium samples: sterile $(\diamond) n=9$; contaminated $(\diamond) n=14 .-$, median concentration.

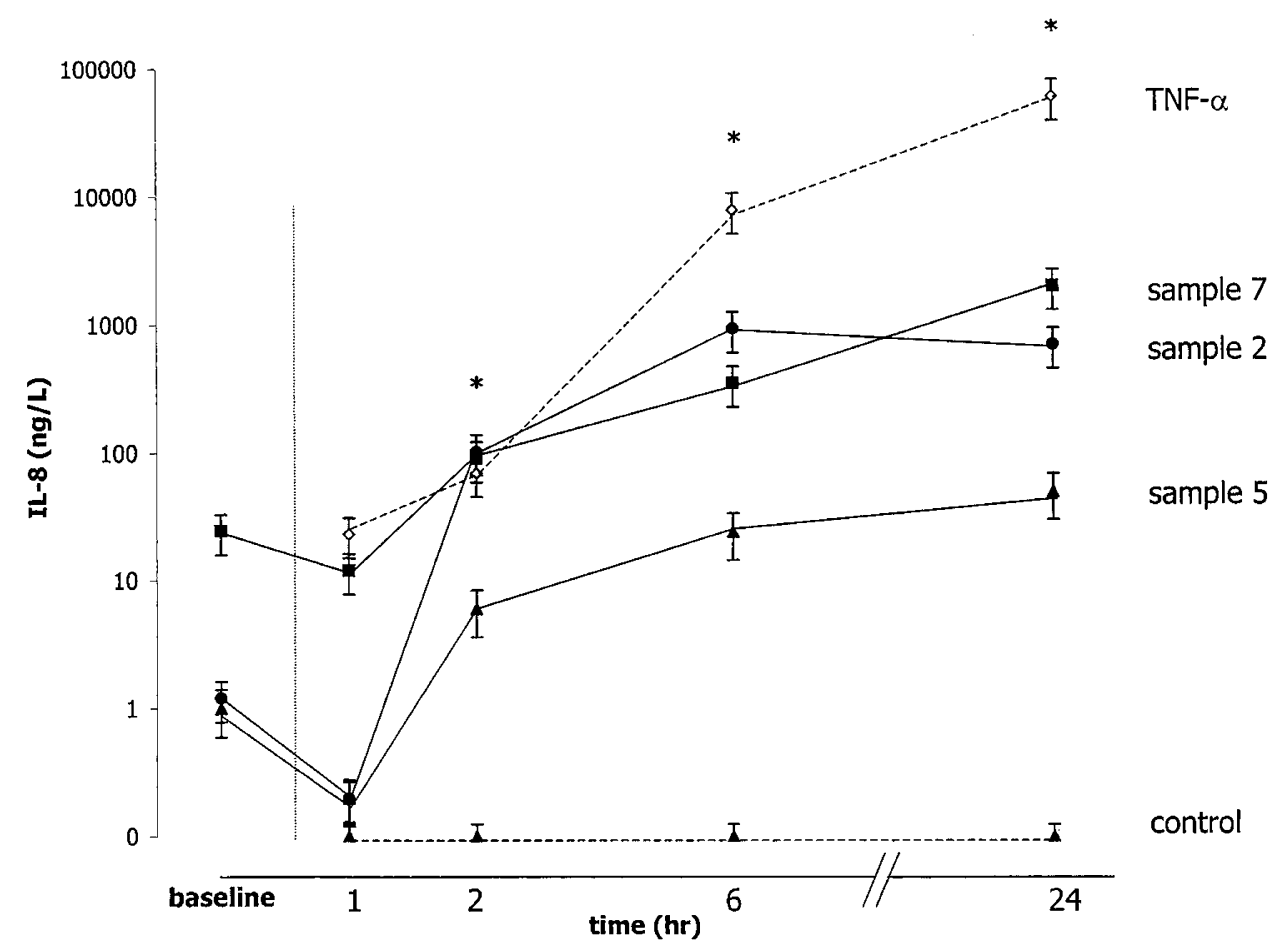

Figure 2. Changes in IL-8 level (ng/L) in supernatant of A549 cells after incubation for the indicated time periods with three sterile meconium samples (numbers 2,5 , and 7), TNF- $\alpha$, or control (RPMI). Data are represented as mean \pm SD. Baseline, IL-8 level in 5-fold diluted meconium samples. ${ }^{*} p<0.01 v s$ baseline.

incubation, further experiments were performed with overnight incubation.

The nine sterile meconium samples were added to cultures of A549 cells. TNF- $\alpha$ levels in the supernatant after overnight incubation of A549 cells with meconium samples ranged from 4 to 31 (median, 11) ng/L in six samples, and TNF- $\alpha$ was below the limit of detection in the other samples. After incubation with the meconium samples, IL-8 levels in the supernatant ranged from 20 to 2240 (median, 80) ng/L (Fig. 3).
IL-8 and TNF- $\alpha$ levels after incubation with heme were, respectively, 180 and $7 \mathrm{ng} / \mathrm{L}$. After incubation of A549 cells with TNF- $\alpha$, IL-8 and TNF- $\alpha$ levels were, respectively, 5300 and $3450 \mathrm{ng} / \mathrm{L}$ (Fig. 3). Overnight incubation with IL-8 resulted in an IL-8 level of $110 \mathrm{ng} / \mathrm{L}$ in the cell culture supernatant whereas TNF- $\alpha$ remained below the detection level (Fig. 3). No correlation was found between IL-8, heme, or TNF- $\alpha$ concentration in the meconium samples and the IL- 8 or TNF- $\alpha$ levels in the culture supernatant. IL- $1 \beta$ and IL- 6 were 


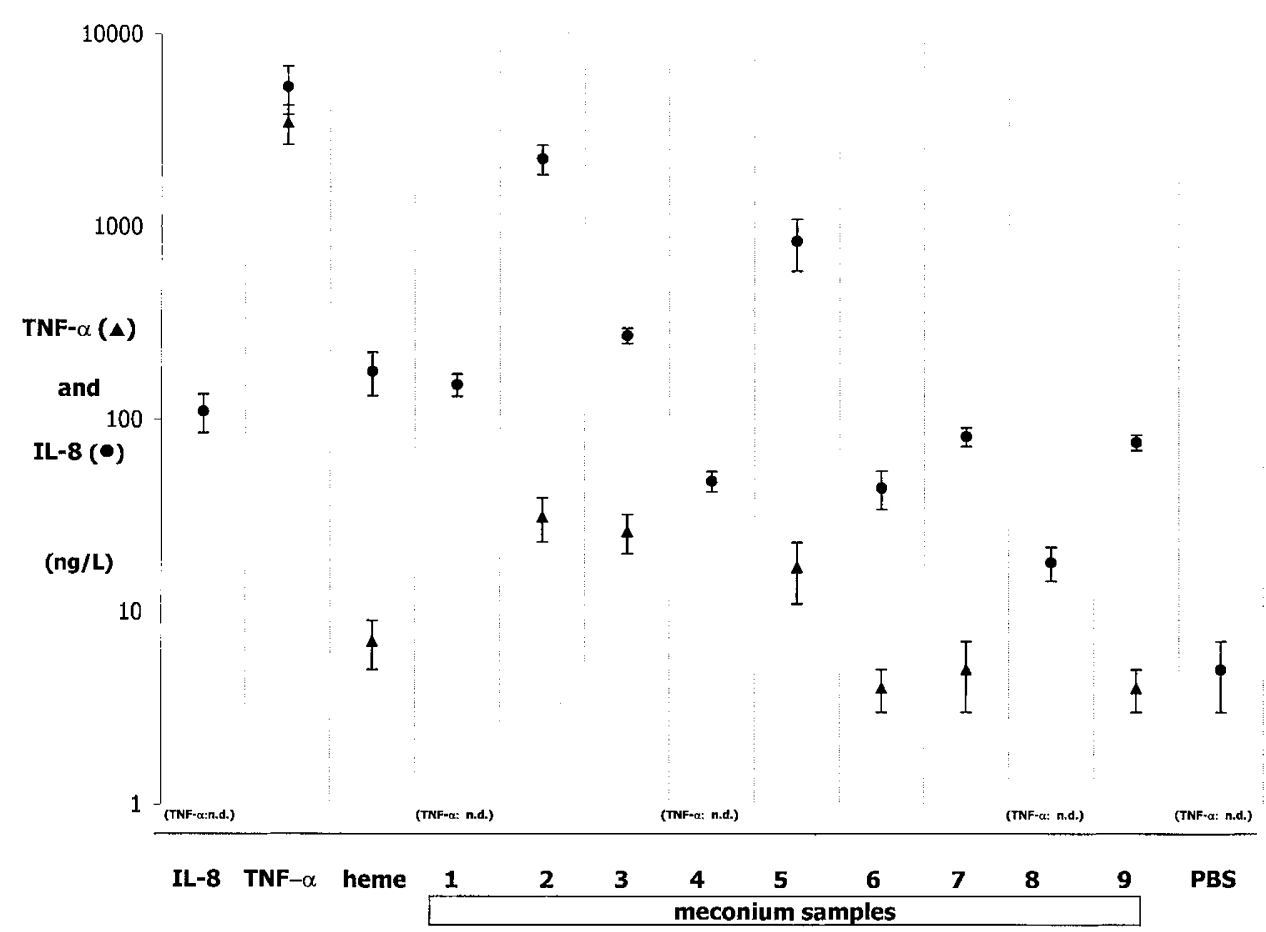

Figure 3. TNF- $\alpha$ and IL-8 levels (ng/L) in supernatant of A549 cell cultures after overnight incubation with IL-8 (20 ng/L), TNF- $\alpha$ (20 ng/L), heme (5 $\mu$ M), nine sterile meconium samples (5-fold diluted, final concentration $20 \mathrm{~g} / \mathrm{L}$ ), or PBS. TNF- $\alpha$ : n.d., not detectable $(<1 \mathrm{ng} / \mathrm{L})$.

not detectable in any of the culture supernatants (data not shown).

\section{DISCUSSION}

Meconium contains variable amounts of proinflammatory substances IL-1 $\beta$, IL-6, IL-8, TNF- $\alpha$, and heme. All studied samples induced IL-8 release and some induced TNF- $\alpha$ release in cultured A549 cells. These new findings help to explain how meconium triggers inflammation in the so-called chemical pneumonitis of MAS and other meconium-related diseases in the newborn $(3,8,9)$.

Aspirated meconium obstructs small airways, causing atelectasis, air trapping, and alveolar inflammation. In addition to conventional therapy, currently available treatment strategies, e.g. inhaled nitric oxide, high-frequency oscillation, and surfactant lavage, may further improve outcome of infants with MAS (10). These treatments all have been shown to have the potential to alleviate the pulmonary inflammatory process in respiratory distress syndrome $(11,12)$. The pathogenesis of the inflammatory response in MAS is not clearly understood. Meconium is a toxic substance that injures respiratory cells and causes a vigorous but transient leukocytic inflammatory reaction in rat lungs (13). Proinflammatory substances, like the chemokine IL-8 and the enzyme phospholipase $\mathrm{A}_{2}(4,14)$, are present in meconium and are capable of eliciting an inflammatory reaction (15). Hydrolysis of membrane and surfactant phospholipids by phospholipase $A_{2}$ will decrease surfactant function and provide substrates for increased production of lipid mediators such as leukotrienes and prostaglandins, each possibly contributing to the inflammatory process in MAS.

In addition, meconium contains a wide array of other substances and cellular degradation products. Recently, heme has been shown to be a proinflammatory mediator in mice by increasing vasopermeability, adhesion molecule expression, and tissue leukocyte infiltration (6). We found that heme was also present in meconium. Our data show that meconium is an extrinsic source of proinflammatory substances. One could speculate that these substances trigger the inflammatory response in vivo and propagate inflammation in the "chemical pneumonitis" in MAS. The reason for the poor correlation of induced cytokine production and the concentration of proinflammatory substances in the meconium is not clear. Perhaps the synergistic interaction of the various cytokines rather than the concentration of a single cytokine determined the response of the A549 cells. Furthermore, it is also possible that antiinflammatory cytokine concentrations are also present in varying concentrations in meconium or that inactivation of cytokine receptors occurred (16).

In some infants the clinical picture of MAS is not evident at birth, but develops slowly in the hours after birth. Stimulation experiments showed a time-dependent release of IL-8 and TNF- $\alpha$ by lung epithelial cells after incubation with meconium. Possibly, the evolution of the full-blown clinical picture reflects the time needed to induce the cytokine release on exposure to meconium.

Inasmuch as bacteria can cause epithelial cytokine release in vitro, we only used sterile meconium samples in our assays to eliminate the risk of bacterial-induced cytokine release (17, 18). In vivo, though, the combination of meconium and bacteria, e.g. group B streptococcus, could aggravate the inflammatory response (19).

On the basis of the presence of IL- 8 and TNF- $\alpha$ in meconium, one might speculate that meconium acts as an exogenous source of cytokines. Possibly, this finding may contribute to the 
development of specific antiinflammatory treatments (20-22). Rabbits treated with anti-IL-8 had an attenuation of the hypotensive and tachypneic effects of LPS and had an increased survival rate after lethal endotoxic shock (23). Others have reported that pretreatment with anti-IL-8 therapy prevents acid-induced alveolar epithelial injury in rabbits (24). AntiIL-8 abolishes the chemotactic effect of meconium in vitro (4).

Cells from the human lung carcinoma cell line A549 are widely used in cytokine research as a model for lung epithelium (25). Because epithelial cells are localized at the interface between host and environment, lung epithelial cells are likely to be exposed to aspirated meconium. On the basis of these considerations and the fact that the A549 cell line is a human cell line, we chose to use this model for our current studies rather than rat type II alveolar cells (model comparable to A549) or alveolar macrophages. In our current study we did not evaluate the effect of anti-cytokine antibodies nor hemebinding substances. Although in vitro data are valuable, they should be used with great caution with respect to applicability to in vivo situations. In vivo studies are needed to specifically address these issues.

\section{CONCLUSION}

In conclusion, we suggest that meconium may trigger the inflammatory cascade in MAS in two ways: directly via cytokines and heme present in meconium and indirectly by inducing cytokine release by the epithelial lung cells.

\section{REFERENCES}

1. Cleary GM, Wiswell TE 1998 Meconium-stained amniotic fluid and the meconium aspiration syndrome. An update. Pediatr Clin North Am 45:511-529

2. Burgess AM, Hutchins GM 1996 Inflammation of the lungs, umbilical cord and placenta associated with meconium passage in utero. Review of 123 autopsied cases. Pathol Res Pract 192:1121-1128

3. Kytola J, Uotila P, Kaapa P 1999 Meconium stimulates cyclooxygenase-2 expression in rat lungs. Prostaglandins Leukot Essent Fatty Acids 60:107-110

4. de Beaufort AJ, Pelikan DM, Elferink JG, Berger HM 1998 Effect of interleukin 8 in meconium on in-vitro neutrophil chemotaxis. Lancet 352:102-105

5. Yamada T, Matsubara S, Minakami H, Kohmura Y, Hiratsuka M, Sato I 2000 Chemotactic activity for polymorphonuclear leukocytes: meconium versus meconium-stained amniotic fluid. Am J Reprod Immunol 44:275-278
6. Wagener FA, Eggert A, Boerman OC, Oyen WJ, Verhofstad A, Abraham NG, Adema G, van Kooyk Y, de Witte T, Figdor CG 2001 Heme is a potent inducer of inflammation in mice and is counteracted by heme oxygenase. Blood 98:1802-1811

7. Zagariya A, Bhat R, Uhal B, Navale S, Freidine M, Vidyasagar D 2000 Cell death and lung cell histology in meconium aspirated newborn rabbit lung. Eur J Pediatr 159:819-826

8. Keski-Nisula L, Aalto ML, Katila ML, Kirkinen P 2000 Intrauterine inflammation at term: a histopathologic study. Hum Pathol 31:841-846

9. Lally KP, Mehall JR, Xue H, Thompson J 1999 Meconium stimulates a proinflammatory response in peritoneal macrophages: implications for meconium peritonitis. J Pediatr Surg 34:214-217

10. Wiswell TE 2001 Advances in the treatment of the meconium aspiration syndrome. Acta Paediatr Suppl 90:28-30

11. Ekekezie II, Thibeault DW, Zwick DL, Rezaiekhaligh MH, Mabry SM, Morgan RE, Norberg M, Truog WE 2000 Independent and combined effects of prolonged inhaled nitric oxide and oxygen on lung inflammation in newborn piglets. Biol Neonate $77: 37-44$

12. Kinsella JP, Parker TA, Galan H, Sheridan BC, Abman SH 1999 Independent and combined effects of inhaled nitric oxide, liquid perfluorochemical, and highfrequency oscillatory ventilation in premature lambs with respiratory distress syndrome. Am J Respir Crit Care Med 159:1220-1227

13. Martinez-Burnes J, Lopez A, Horney B, MacKenzie A, Brimacombe M 2001 Cytologic and biochemical changes associated with inoculation of amniotic fluid and meconium into lungs of neonatal rats. Am J Vet Res 62:1636-1641

14. Schrama AJ, de Beaufort AJ, Sukul YR, Jansen SM, Poorthuis BJ, Berger HM 2001 Phospholipase $\mathrm{A}_{2}$ is present in meconium and inhibits the activity of pulmonary surfactant: an in vitro study Acta Paediatr 90:412-416

15. Holopainen R, Aho H, Laine J, Peuravuori H, Soukka H, Kaapa P 1999 Human meconium has high phospholipase $\mathrm{A}_{2}$ activity and induces cellular injury and apoptosis in piglet lungs. Pediatr Res 46:626-632

16. Oleksy A, Banbula A, Bugno M, Travis J, Potempa J 2002 Proteolysis of interleukin-6 receptor (IL-6R) by Porphyromonas gingivalis cysteine proteinases (gingipains) inhibits interleukin-6-mediated cell activation. Microb Pathog 32:173-181

17. Doran KS, Chang JC, Benoit VM, Eckmann L, Nizet V 2002 Group B streptococcal beta-hemolysin/cytolysin promotes invasion of human lung epithelial cells and the release of interleukin-8. J Infect Dis 185:196-203

18. Larsson BM, Larsson K, Malmberg P, Palmberg L 1999 Gram positive bacteria induce IL-6 and IL-8 production in human alveolar macrophages and epithelial cells. Inflammation 23:217-230

19. Speer CP, Groneck P 1998 Oxygen radicals, cytokines, adhesion molecules and lung injury in neonates. Semin Neonatol 3:219-228

20. Taylor PC, Williams RO, Maini RN 2001 Immunotherapy for rheumatoid arthritis. Curr Opin Immunol 13:611-616

21. van Dullemen HM, Van Deventer SJ, Hommes DW, Bijl HA, Jansen J, Tytgat GN, Woody J 1995 Treatment of Crohn's disease with anti-tumor necrosis factor chimeric monoclonal antibody (cA2). Gastroenterology 109:129-135

22. Yang XD, Corvalan JR, Wang P, Roy CM, Davis CG 1999 Fully human antiinterleukin-8 monoclonal antibodies: potential therapeutics for the treatment of inflammatory disease states. J Leukoc Biol 66:401-410

23. Carvalho GL, Wakabayashi G, Shimazu M, Karahashi T, Yoshida M, Yamamoto S, Matsushima K, Mukaida N, Clark BD, Takabayashi T, Brandt CT, Kitajima M 1997 Anti-interleukin-8 monoclonal antibody reduces free radical production and improves hemodynamics and survival rate in endotoxic shock in rabbits. Surgery 122:60-68

24. Modelska K, Pittet JF, Folkesson HG, Courtney B, V, Matthay MA 1999 Acidinduced lung injury: protective effect of anti-interleukin-8 pretreatment on alveolar epithelial barrier function in rabbits. Am J Respir Crit Care Med 160:1450-1456

25. Kwon OJ, Au BT, Collins PD, Adcock IM, Mak JC, Robbins RR, Chung KF, Barnes PJ 1994 Tumor necrosis factor-induced interleukin-8 expression in cultured human airway epithelial cells. Am J Physiol 267:L398-L405 